\title{
Distribution of causes of abnormal uterine bleeding using new FIGO classification system-PALM COEIN: a rural tertiary hospital based study
}

\author{
Kalpana Betha*, Lavanya Malavatu, Sreeveena Talasani
}

SHARE INDIA, Mediciti Institute of Medical Sciences, Hyderabad, Telangana, India

Received: 01 June 2017

Accepted: 27 June 2017

*Correspondence:

Dr. Kalpana Betha,

E-mail: kalpanabasany@gmail.com

Copyright: () the author(s), publisher and licensee Medip Academy. This is an open-access article distributed under the terms of the Creative Commons Attribution Non-Commercial License, which permits unrestricted non-commercial use, distribution, and reproduction in any medium, provided the original work is properly cited.

\begin{abstract}
Background: Abnormal Uterine Bleeding (AUB) is a significant debilitating clinical condition. It may have a significant impact on women's quality of life with significant burden to the country's economy. The primary aim was to categorize women with Abnormal Uterine Bleeding (AUB) according to PALM COEIN classification system and to correlate the clinical diagnosis and histopathologic features of various causes of AUB.

Methods: A retrospective study was carried out on 250 non-gravid reproductive age women between 25-45 years with complaints of AUB at Mediciti Institute of Medical Sciences, a rural tertiary teaching hospital during the period January 2014 to December 2015.

Results: The PALM and COEIN groups accounted for $60.4 \%$ and $39.6 \%$ respectively. Leiomyoma was the most common cause of AUB (30.4\%) and Ovulatory disorders was the 2nd most common cause of AUB (13.6\%). A total of $172(68.8 \%)$ were classified as having chronic AUB and 78(31.2\%) as having acute AUB. In AUB-L, the difference in clinical and histopathological diagnosis was significant $(\mathrm{p}=0.03)$.

Conclusions: Structural causes of AUB contributed more to the cause of AUB. The PALM COEIN classification system helps us in understanding various etiological causes of AUB and can be used by clinicians and researchers for international comparisons.
\end{abstract}

Keywords: Abnormal Uterine Bleeding, Clinical, COEIN, Histopathology, PALM

\section{INTRODUCTION}

Abnormal Uterine Bleeding (AUB) is a significant debilitating clinical condition and affects $14-25 \%$ of women of reproductive age and up to $50 \%$ of perimenopausal women. ${ }^{1-3}$ It may have a significant impact on women's personal, social, physical and quality of life with significant financial burden to the country's economy. ${ }^{4}$ Acute AUB is defined as bleeding in a nonpregnant woman of reproductive age of sufficient quantity to require immediate intervention to prevent further loss. ${ }^{5,6}$ Chronic AUB is defined as bleeding from the uterine corpus that is abnormal in duration, volume, and/or frequency and has been present for most of the previous 6 months. 5

Historical literature of AUB reveals no universally accepted method for classifying AUB, which hampered the investigation and categorization of possible etiologies of AUB. ${ }^{7}$ The classic terminology that describes AUB include terms that are not related to the underlying etiology (e.g., menorrhagia, polymenorrhea etc.). In order to standardize definitions, nomenclature and the possible underlying etiologies of AUB, it was redefined by International Federation of Obstetrics and Gynecology (FIGO) in 2009 by the FIGO Menstrual Disorders 
Group(FMDG). ${ }^{5,6}$ This would simplify the investigation and comparison among homogenous populations and aid in research and evidence based approach to AUB. The FIGO categorized AUB based on structured medical history, laboratory tests, Ultrasound and or hysteroscopy based techniques. ${ }^{5}$ The classification is based on the acronym "PALM- COEIN", which stands for Polyp, Adenomyosis, Leiomyoma, Malignancy (and Hyperplasia) and comprises structural pathologies assessed visually. ${ }^{5}$ The COEIN group stands for coagulopathy, ovulatory disorders, endometrial, iatrogenic, not otherwise classified and relates to non structural etiologies that cannot be assessed by imaging or histopathology. ${ }^{5}$ Leiomyomas (fibroids) are again sub divided, depending on the location, into submucosal $(\mathrm{SM})$ and other $(\mathrm{O})$ and then further into nine categories according to Wamsteker classification. ${ }^{8}$

The primary aim of the present study was to categorize women with AUB according to PALM- COEIN system. A secondary aim was to correlate the clinical diagnosis and pathologic features of various causes of AUB.

\section{METHODS}

The present study was conducted at Mediciti Institute of Medical Sciences, a rural tertiary teaching hospital, Telangana State, India from January 2014 to December 2015. A total of 250 non-gravid women of reproductive age between 25- 45 years were included. Women who were pregnant, women with obvious cervical cause of bleeding per vaginum and with local lesions on vagina and vulva were excluded from the study. The study was approved by the Institutional Ethics Committee. Data was collected using a pre-tested proforma meeting the objectives of the study with their consent. Patient's demographic details were collected. Structured history followed by general physical, systemic and gynecological examination was carried out. On gynecological examination, external genitalia, cervix, uterus and adnexae were assessed. A pelvic ultrasound was done to assess uterus and adnexae for any pathology. Endometrial biopsy and hysterectomy specimens were obtained for histopathology where applicable. The gross and microscopic findings of the hysterectomy samples were obtained. The causes were categorized according to PALM-COEIN and clinical diagnosis was then correlated with histopathology based final diagnosis of AUB. The PALM group were classified as per the structural abnormality noted. The COEIN group were classified where no structural alterations were appreciated. Coagulopathy was labelled for all known cases of coagulation. Bleeding time, Clotting time was done for all cases. Prothrombin time, Activated Partial Thromboplastin Time were done wherever required. Ovulatory disorder was defined as unpredictable timing and variable amount of bleeding. Endometrial disorders were referred to causes where predictable or cyclical pattern of bleeding was observed. Iatrogenic category was categorized by onset of symptoms following use of hormonal steroids or contraceptive device/method in the preceding 3 months. The rest were included in the not yet classified category.

\section{Statistical analysis}

The data was analyzed using SPSS version 16.0 and descriptive statistics were analyzed using frequencies, percentages and chi square tests.

\section{RESULTS}

During the study period, a total of 250 women of reproductive age (25-45 y) with complaints of AUB were assessed.

Table 1: Characteristics of participants $(n=250)$.

\begin{tabular}{|lll|}
\hline Characteristic & Number & $\%$ \\
\hline Age in years & & \\
\hline $25-30$ & 44 & 17.6 \\
\hline $31-35$ & 33 & 13.2 \\
\hline $36-40$ & 68 & 27.2 \\
\hline $41-45$ & 105 & 42 \\
\hline Parity & & \\
\hline Nulliparous & 3 & 1.2 \\
\hline 1 & 33 & 13.2 \\
\hline 2 & 110 & 44 \\
\hline 3 & 91 & 36.4 \\
\hline 4 and above & 13 & 5.2 \\
\hline BMI & & \\
\hline Underweight & 3 & 1.2 \\
\hline Normal & 49 & 19.6 \\
\hline Overweight & 54 & 21.6 \\
\hline Obese & 144 & 57.6 \\
\hline
\end{tabular}

Table 1 shows the participants characteristics. Almost half of the women $(42 \%)$ were in the age group 4145years and $85 \%$ of the women with AUB were multiparous. More than half of the women $(58 \%)$ were obese. A total of $172(68.8 \%)$ were classified as having chronic AUB and $78(31.2 \%)$ as having acute AUB. Single pathology was seen in $58 \%$ of women while $40 \%$ of women had multiple etiologies as a cause of AUB.

Table 2 illustrates distribution of women with AUB. The PALM and COEIN groups accounted for $60.4 \%$ and $39.6 \%$ respectively. Leiomyoma was the most common cause of AUB (30.4\%) and Ovulatory disorders was the 2nd most common cause of AUB (13.6\%). A total of 26 polyps were identified, of which $8(30.7 \%)$ were cervical polyps, while $18(69.3 \%)$ were endometrial polyps. Histopathology of endometrium in women with polyps showed proliferative phase in 16 cases (61.51\%), secretory phase in $8(30.7 \%)$ cases. A total of 30 women were diagnosed with adenomyosis, of whom $18(60 \%)$ had diffuse adenomyosis, while 12 had focal adenomyosis. The histopathology of endometrium in 
adenomyosis showed secretory phase in 16 cases $(53.3 \%)$ and proliferative phase in $11(36.6 \%)$ women.

Table 2: The distribution of women with AUB.

\begin{tabular}{|llll|}
\hline Diagnosis & No. & $\%$ & Notation \\
\hline PALM & 151 & 60.4 & \\
\hline Polyp & 26 & 10.4 & AUB-P \\
\hline Adenomyosis & 30 & 12 & AUB-A \\
\hline Leiomyoma & 76 & 30.4 & AUB-L \\
\hline Malignancy (and hyperplasia) & 19 & 7.6 & AUB-M \\
\hline COEIN & 99 & 31.6 & \\
\hline Coagulpathy & 2 & 0.8 & AUB-C \\
\hline Ovulatory & 34 & 13.6 & AUB-O \\
\hline Endometrial & 30 & 12 & AUB-E \\
\hline Iatrogenic & 29 & 11.6 & AUB-I \\
\hline Not yet classified & 4 & 1.6 & AUB-N \\
\hline
\end{tabular}

Table 2 illustrates distribution of women with AUB. The PALM and COEIN groups accounted for $60.4 \%$ and $39.6 \%$ respectively. Leiomyoma was the most common cause of AUB (30.4\%) and Ovulatory disorders was the 2nd most common cause of AUB (13.6\%). A total of 26 polyps were identified, of which $8(30.7 \%)$ were cervical polyps, while $18(69.3 \%)$ were endometrial polyps. Histopathology of endometrium in women with polyps showed proliferative phase in 16 cases (61.51\%), secretory phase in $8(30.7 \%)$ cases. A total of 30 women were diagnosed with adenomyosis, of whom 18 (60\%) had diffuse adenomyosis, while 12 had focal adenomyosis. The histopathology of endometrium in adenomyosis showed secretory phase in 16 cases $(53.3 \%)$ and proliferative phase in $11(36.6 \%)$ women.

Table 3: Correlation of clinical and histopathological based diagnosis of AUB.

\begin{tabular}{|llll|}
\hline Category & $\begin{array}{l}\text { Clinical } \\
\text { PALM } \\
\text { n=151 } \\
(60.4 \%)\end{array}$ & $\begin{array}{l}\text { Histopathology } \\
\text { PALM } \\
\text { n=190 }\end{array}$ & $\begin{array}{l}\text { P } \\
\text { value } \\
0.003\end{array}$ \\
\hline Polyp & 26 & 32 & 0.48 \\
\hline Adenomyosis & 30 & 38 & 0.36 \\
\hline Leiomyoma & 76 & 100 & 0.03 \\
\hline $\begin{array}{l}\text { Malignancy } \\
\text { and }\end{array}$ & 19 & 20 & \\
\begin{tabular}{l} 
Hyperplasia) \\
\hline
\end{tabular} & $\begin{array}{l}\mathrm{COEIN} \\
\mathrm{n}=99\end{array}$ & $\begin{array}{l}\mathrm{COEIN} \\
\mathrm{n}=60\end{array}$ & 0.003 \\
\hline $\begin{array}{l}\text { Ovulatory } \\
\text { disorder }\end{array}$ & 34 & 38 & 0.70 \\
\hline Endometrial & 30 & 22 & 0.30 \\
\hline
\end{tabular}

Leiomyomas were identified in 76 (30.4\%) women, of which 24 were submucosal. Secretory phase of endometrium was identified in $42(55.2 \%)$ of women with leiomyoma and proliferative phase of endometrium in $29(38.1 \%)$ women. Among 19 women diagnosed with malignancy and hyperplasia, 9 were diagnosed with simple hyperplasia without atypia, 2 women with simple hyperplasia with atypia, 2 women with complex hyperplasia without atypia and one woman had complex hyperplasia with atypia. Only 3 women were diagnosed with endometrial carcinoma.

Table 3 shows correlation of clinical and histopathology based diagnosis of AUB. On histopathological diagnosis, PALM causes of AUB accounted for 190/250 (76\%). The AUB-O and AUB-E of COEIN group accounted for $60 / 250(24 \%)$. The difference was significant statistically $(\mathrm{p}<0.05)$ on clinical and histopathological correlation. Histopathology could diagnose more cases of leiomyoma compared to other causes of AUB and the difference was found to be statistically significant.

\section{DISCUSSION}

The study was undertaken to stratify the causes of AUB based on PALM COEIN classification and to correlate the clinical and histopathology features so as to know the precise etiology of AUB for successful management of AUB. AUB was seen mostly between 41-45 years, similar to a study by Arnold et al. ${ }^{9}$ The transition from ovulatory cycles to menopause begins in late 40's. There will be rise in FSH levels leading to increased ovarian follicular response and high estrogen levels. The accelerated loss of ovarian follicles causes episode of anovulation, leading to irregular, unpredicted pattern of bleeding. ${ }^{10}$

More than half of the women $(57.6 \%)$ in the present study were obese. In obesity, the excessive adipose tissue increases peripheral aromatization of androstenedione to estrone. ${ }^{11}$ In premenopausal women, elevated estrone levels trigger abnormal feedback in the hypothalamo pituitary axis causing oligo or anovulation. In the absence of ovulation, the endometrium is exposed to continuous estrogen stimulation.

Most of the study subjects $(68.8 \%)$ were diagnosed with chronic AUB as these women might have assumed initial episodes of AUB as normal in the perimenopausal age group. And also, as $60 \%$ of women in the present study had structural causes, these women presented with chronic symptoms.

Though majority of polyps are asymptomatic, the contribution to AUB varies from $3.7 \%$ to $65 \% .^{12}$ In the present study, $10.4 \%$ of cases of AUB was caused by polyps. Similarly, study done by Doraiswamy et al also showed that polyps accounted for $11.2 \%$ cases of AUB. ${ }^{13}$ The histopathology of endometrium showed proliferative phase which indicates that their growth is estrogen regulated.

The cause of AUB in adenomyosis is unclear but 30 $(12 \%)$ women were diagnosed with adenomyosis, similar to Qureshi et al study where $15 \%$ cases of AUB had 
adenomyosis. ${ }^{12,14}$ It is one of the common cause of AUB between 35-45 years. Multiparous women had high incidence of adenomyosis with diffuse subtype predominating. Pregnancy might facilitate the formation of adenomyosis by allowing adenomyotic foci to be included in the myometrium due to the invasive nature of the trophoblast on the extension of myometrial fibres. ${ }^{15,16}$ In addition, adenomyotic tissue may have a higher ratio of estrogen receptors and the hormonal milieu of pregnancy may favour the development of islands of ectopic endometrium. According to Tarun et al, 70 to $80 \%$ of women undergoing hysterectomy for adenomyosis are in their fourth and fifth decade of life and are multiparous. ${ }^{17}$

In the reproductive age women, the incidence of uterine leiomyomas has been shown to be as high as $70-80 \%$ in studies using histologic/sonographic examination. ${ }^{18}$ Leiomyoma was the most predominant cause of AUB $(30.4 \%)$ in the present study. Similarly, Mishra et al and others have shown leiomyoma as the most common cause of AUB. ${ }^{10,14,19}$ There is increase in incidence of fibroids with increasing age, majority of them were seen between 41-45 years. Leiomyomas are sub classified based on the site as submucosal (L-SM) and others (L-O). Intramural and subserosal types constituted $60.5 \%$ of leiomyomas in the present study, similar to Arnold et al study. ${ }^{9}$ It was thought that women with submucous fibroids that distort the cavity were most likely to cause heavy menstrual bleeding (HMB), though the present study showed intramural type to be associated with $\mathrm{HMB} .{ }^{20} \mathrm{HMB}$ may be due to increased endometrial surface area, hyperestrogenemia causing endometrial hyperplasia, presence of fragile and engorged vasculature in the perimyoma tissue release of angiogenic factors like vascular endothelial growth factor (VEGF), plateletderived growth factor (PDGF), which impair local endometrial hemostasis. ${ }^{20}$

Endometrial hyperplasia, which involves proliferation of endometrial glands and its progression to endometrial carcinoma can cause AUB. ${ }^{4}$ Premenopausal women with obesity and chronic anovulation are the risk factors observed in the present study. As endometrial cancers are common in the age group 50-60 years, the AUB-M was seen in only $7.6 \%$ of cases, similar to Qureshi et al study and Mishra et al study. ${ }^{10,14}$

Although coagulopathies are reported to affect $13 \%$ of women presenting with AUB, the present study had only 2 cases $(0.8 \%)$, similar to Qureshi et al study $(0.3 \%){ }^{14}$ Ovulatory dysfunction manifests with unpredictable timing and variable amount of flow and in some instances with HMB. ${ }^{14}$ Ovulatory dysfunction was the $2^{\text {nd }}$ most common cause of AUB (13.6\%) in the present study and Arnold et al study had $17.2 \%$ of cases. ${ }^{9}$ Endometrial cause of AUB is a diagnosis of exclusion. A primary disorder of the endometrium may be due to aberrant prostaglandin synthesis and excessive plasminogen. ${ }^{21}$ The endometrial causes of AUB were similar in the present study (12\%) and Mishra et al study (12.2\%). ${ }^{10}$ Many episodes of unscheduled bleeding are related to exogenous therapy. ${ }^{12}$ Medications like anticonvulsants, hormonal steroids may have direct impact on ovulation. Intrauterine contraceptive device (IUD) may cause low grade endometritis and also cause unbalanced ratios of prostaglandins and thromboxanes which may contribute to AUB. ${ }^{12}$ Iatrogenic causes contributed to $11.6 \%$ of cases of AUB. The category not yet classified is reserved for entities like chronic endometritis, myometrial hypertrophy which contributed to $1.6 \%$ of cases.

Clinical and histopathological correlation of PALM COEIN showed significantly more cases to have structural causes of AUB on histopathological diagnosis compared to clinical diagnosis. The difference in clinical and histopathological diagnosis of polyp was not significant $(p=0.48)$. Similar findings were observed in Mishra et al study $(\mathrm{p}>0.05) .{ }^{10}$ This may be explained by the fact that endometrial polyps were not missed on imaging. Contrary to this, Khan et al study found difference to be highly significant for polyps. ${ }^{22}$ In AUBA, the difference was not significant $(\mathrm{p}=0.36)$ as adenomyosis can be easily diagnosed by history and clinical examination. However, significant findings were observed in other studies in cases of adenomyosis. ${ }^{10,23}$ In AUB-L, the difference was significant $(\mathrm{p}=0.03)$. The emphasis of histopathological examination should be a complementary diagnostic aid in diagnosing PALM causes of AUB. In AUB-M, the difference was not significant $(p=1)$ as only 19 women with AUB had malignancy and hyperplasia. Though the difference is not significant in the present study, histopathological diagnosis is mandatory in clinical suspected cases of AUB. In AUB-O and AUB-E the difference was not significant $(p=0.7,0.3)$ respectively.

There are not many studies showing causes of AUB according to PALM COEIN system. This sort of analysis will enable us to have a better understanding of the etiology of AUB to develop effective management strategies. The women with symptomatic AUB were only taken in to the study as few of the structural causes of AUB may be asymptomatic. The sample size was small. Tests for Von Willebrand factor to identify patients with coagulopathy were not routinely done. The characterization of structural lesions of the uterus using MRI was not done because of the cost and therefore tertiary classification of leiomyoma was not done in the present study.

\section{CONCLUSION}

Structural causes of AUB contributed more to the cause of AUB clinically. Histopathological diagnosis also revealed structural causes to be the major contributor of AUB in reproductive aged women. On clinical and histopathological correlation, the difference in clinical and histopathological diagnosis was statistically significant for leiomyoma. The PALM COEIN 
classification system helps us in understanding various etiological causes of AUB and can be used by clinicians to facilitate comparisons and research.

\section{ACKNOWLEDGMENTS}

Authors would like to thank all the women who participated in the study.

Funding: No funding sources

Conflict of interest: None declared

Ethical approval: The study was approved by the Institutional Ethics Committee

\section{REFERENCES}

1. Fraser IS, Langham S, Uhl-Hochgraeber K. Healthrelated quality of life and economic burden of abnormal uterine bleeding. Expert Rev Obstet Gynecol. 2009;4:179-89.

2. Shapley M, Jordan K, Croft PR. An epidemiological survey of symptoms of menstrual loss in the community. Br J Gen Pract. 2004;54:359-63.

3. Hoffman BL. Williams Gynecology. $2^{\text {nd }}$ ed. p.a Mc Graw Hill;2012:219-40.

4. NICE. Clinical Guideline 44; Heavy menstrual bleeding 2007. National Institute for Health and Clinical Excellence (NICE); Available at http://www.nice.org.uk/nicemedia/pdf/CG44FullGui deline.pdf.

5. Munro MG, Critchley HO, Broder MS, Fraser IS, FIGO Working Group on Menstrual Disorders System. FIGO classification system (PALM-COEIN) for causes of abnormal uterine bleeding in nongravid women of reproductive age. Int $\mathbf{J}$ Gynecol Obstet. 2011;113(1):3-13.

6. Fraser IS, Critchley HO, Broder M, Munro MG. The FIGO recommendations on terminologies and definitions for normal and abnormal uterine bleeding. Semin Reprod Med. 2011;29(5):383-90.

7. Woolcock JG, Critchley HO, Munro MG, Broder MS, Fraser IS. Review of the confusion in current and historical terminology and definitions for disturbances of menstrual bleeding. Fertil Steril. 2008;90(6):2269-80.

8. Wamsteker K, Emanuel MH, de Kruif JH. Transcervical hysteroscopic resection of submucous fibroids for abnormal uterine bleeding: results regarding the degree of intramural extension. Obstet Gynecol. 1993;82:736-40.

9. Jonathan AA, Saravanan S. A two year clinicopathological study of non-gravid women with abnormal uterine bleeding in a rural tertiary care centre in Tamilnadu: in concurrence with the Figo recommendations. J Evol Med Dental Sci. 2015;4(63):10990-1001.
10. Mishra D, Sultan S. FIGO's PALM-COEIN Classification of Abnormal Uterine Bleeding: A Clinico-histopathological Correlation in Indian Setting. J Obstet Gynecol India. 2017;67(2):119-25.

11. Hoffman BL. Williams Gynecology. $2^{\text {nd }}$ ed. Mc Graw Hill; 2012:463.

12. Whitaker L, Critchley HO. Abnormal uterine bleeding. Best Pract Res Clin Obstet Gynaecol. 2016;34:54-65.

13. Doraiswami S, Johnson T, Rao S, Rajkumar A, Vijayaraghavan J, Panicker VK. Study of endometrial pathology in abnormal uterine bleeding. J Obstet Gynaecol India. 2011;61(4):426-30.

14. Qureshi FU, Yusuf AW. Distribution of causes of abnormal uterine bleeding using the new FIGO classification system. JPMA. 2013;63(973).

15. Templeman C, Marshall SF, Ursin G, Horn-Ross PL, Clarke CA, Allen $M$ et al. Adenomyosis and endometriosis in the California Teachers Study. Fertil Steril. 2008;90(2):415-24.

16. Weiss G, Maseelall P, Schott LL, Brockwell SE, Schocken M, Johnston JM. Adenomyosis a variant, not a disease? Evidence from hysterectomized menopausal women in the Study of Women's Health Across the Nation (SWAN). Fertil Steril. 2009;91(1):201-6.

17. Taran FA, Weaver AL, Coddington CC, Stewart EA. Characteristics indicating adenomyosis coexisting with leiomyomas: a case control study. Hum Reprod. 2010;1177-82.

18. Hoffman BL. Williams Gynecology. $2^{\text {nd }}$ ed. Mc Graw Hill;2012:247.

19. Perveen S, Perveen S. Endometrium histology in abnormal uterine bleeding. Q Med Channel. 2011;17(4):68-70.

20. Munro MG. Classification of menstrual bleeding disorders. Rev Endocr Metab Disord. 2012;13:22534.

21. Shankar M, Lee CA, Sabin CA, Economides DL, Kadir RA. von Willebrand disease in women with menorrhagia: a systematic review. BJOG 2004;111:734-40.

22. Khan S, Hameed S, Umber A. Histopathological pattern of endometrium on diagnostic D and C in patients with abnormal uterine bleeding. ANNALS. 2011;17(2):166-70.

23. Ramachandran T, Subarmanium SP. Correlation between clinico-pathological and ultrasonographical findings. J Clin Diagn Res. 2011;5(4):737-40.

Cite this article as: Betha K, Malavatu L, Talasani

S. Distribution of causes of abnormal uterine bleeding using new FIGO classification system-

PALM COEIN: a rural tertiary hospital based study. Int J Reprod Contracept Obstet Gynecol 2017;6:3523-7. 